\title{
The future of EU sports law and policy
}

A central objective of this text was to place some order on the seemingly random and ad hoc impulses of EU activity in the sports sector. The book claims that today's EU sports policy has developed out of a policy tension within the EU. The tension between the Single Market regulatory impulses of EU activity in sport and the EU's political policy objectives for sport has contributed to the birth of a EU sports policy defined by the construction of the separate territories approach. In other words a distinct legal approach to sport has emerged. This implies the birth of EU sports law, which has had the result of shifting the nature of sports regulation towards a socio-cultural model of regulation. EU interventions in sport do not simply reflect a desire to correct market distortions or restrictions. Judicial intervention is sensitive to the requirements of current EU sports policy. As such, it is no longer appropriate to refer to the EU's regulation of sport as an example of sport and the law. Rather, by defining separate territories of sporting autonomy and judicial intervention, the EU has constructed a discrete body of law relating specifically to sport, hence the term sports law.

Why is the distinction between sport and the law and sports law important? On the face of it this may appear another one of those semantic and essentially pointless distinctions that is of academic interest only. Analysing the relationship between these concepts is however fundamental for understanding the future direction of EU sports policy. Academics, legal practitioners and sports administrators can trawl through EU case law and sports-related policy papers in order to form a view of where the relationship between sport and the EU currently stands. Although a rather timeconsuming exercise, it is nonetheless a worthwhile exercise. However, in order to understand how the relationship between sport and the EU emerged and in what direction EU sports law and policy is heading, some further analysis is required. 


\section{Theoretical contributions}

As explained in Chapter 2, an obvious gap in the sports law literature is the lack of theoretical investigation. This poses some problems for the credibility of the sports law thesis. Not only will a lack of theoretical underpinning inhibit the development of sports law as an academic discipline, it also leaves more practical questions about the future either unexplored or directionless. The concept of sports law is in its infancy. The sub-branch of EU sports law is even more nascent. The search for theory is therefore inhibited by a lack case law.

The prudent or more cautious could make a case for taking further time to reflect on developments in the EU. The task of attempting to construct an approach offering insights into the sports law phenomenon is not however a premature exercise. First, although not vast, sufficient empirical material exists to allow for the construction of ideas. The small amount of 'hard' law since 1999 combined with the proliferation in 'soft' law is sufficient to identify the emergence of EU sports law and policy. Second, EU involvement in new sectors offers political scientists and lawyers an excellent opportunity to test and refine existing theories of European integration. Third, if it is accepted that the EU's approach to sports regulation has changed in favour of a socio-cultural model, then it must remain a possibility for the future that the approach will change again. Greater theoretical investigation will illuminate the possible future contours of EU sports law and policy. Finally, the debate on the relationship between sport and the EU is a current one. The way in which the EU deals with sport tells us much about the type of organisation the EU wants to be. A major constitutional review of the EU's activities is currently under way with a view to further Treaty revision in $2004 .{ }^{1}$ Sports location within the EU's constitutional structure post-2004 will be dependent on the activities of the two advocacy coalitions working within the sports policy subsystem. The sports policy subsystem is not a non-neutral arena existing simply to process inputs into outputs in an apolitical manner. Rather activity within it will determine sports future legal and constitutional status. The need to construct better empirical and theoretical understandings of the subsystem is therefore paramount.

The main theoretical contribution advanced in this book is the need for subsystem analysis. The approach presented here rejects the notion of monolithic EU institutions slugging it out between themselves for control over policy. Rather, it is argued that the EU is best characterised as a multi-level organisation in which a myriad of policy-specific subsystems exist. Activity within subsystems determines the nature of the policy output. The analysis therefore centres on the nature of the subsystem. If a better understanding of the subsystem can be developed, more accurate hypotheses about the future direction of policy can be advanced. Subsystem analysis requires two focuses. First, the actors within the subsystem need identifying and their 
belief systems specifying. Second, the institutional resources at the disposal of the actors need identifying.

\section{Actors}

The actors within the sports policy subsystem are organised into two advocacy coalitions. The belief system of the Single Market coalition is imbued with the logic of negative integration and Single Market regulation. In other words, the manner in which law is applied to sport should not allow the principles of the four freedoms to be undermined. The belief system of the sociocultural coalition is held together by the logic of positive integration and a commitment to the socio-cultural model of sports regulation. Sport possesses social and cultural characteristics which necessitates a soft touch application of law. Furthermore, the market-based definition of sport adopted by the Single Market regulators conflicts with the socio-cultural coalition's concern to develop a people's Europe. Membership of the two advocacy coalitions is wide. The term 'actor' refers to those who are actively involved in the policy debate. This includes EU institutions either acting as discrete entities such as the ECJ, the Commission or the Parliament, or as individual components within institutions such as individual Directorates General within the Commission, individual committees within the Parliament and individual Presidencies within the context of intergovernmental forums. However, as previously explained, the term 'actor' should not be confused with 'institution'. The ECJ, Commission and Parliament are considered to be actors within the subsystem. The institutionalist element of the otherwise actor-centred approach stems not from their mere involvement within the subsystem as actors, but from the characteristics they bring to the subsystem. Institutions not only bring formal policy instruments and procedures to the subsystem, they also bring informal, cultural and normative resources to it (see below).

The Single Market coalition, consisting primarily of the ECJ and the Competition Policy Directorate, do not pursue a specific sports-related agenda. Their policy interest in sport is regulatory. Their key concern is for the protection of the four freedoms. The socio-cultural coalition was formed with particular sporting goals in mind. The key actors include the Parliament, the Education and Culture Directorate, the member states and a wide range of sports bodies. However, the coalition is a coalition of convenience given the differences within the secondary aspects of the belief system. In particular, strategic differences exist over (1) the extent to which sport should seek protection from EU law; (2) the method of achieving protection; and (3) the wider (and more controversial) issue of the desirability of a legally rooted common EU sports policy.

\section{Institutional resources}

The ability of the rival advocacy coalitions to achieve policy results consistent with their belief system depends on the extent to which they are 
institutionally well resourced. In other words, do they possess the ability to re-direct policy? Coalitions seek to re-direct policy through the exploitation of institutional venues - hence the need for an actor-centred brand of institutionalism. If actors are unsuccessful in one venue, a well-resourced coalition will go venue shopping in another. The term institutional venue refers not only to the formal administrative, legal and political dimensions of institutions, but also the informal arenas of political systems such as informal rules, norms, symbols, beliefs and codes of conduct.

The Single Market coalition is well resourced. Their belief system is strongly rooted, both legally and culturally, within the Treaty. Legally, the logic of negative integration is underpinned by the EU's legal system, particularly the provisions relating to the four freedoms and competition policy. The ECJ and the Commission also have a strong role in implementing and enforcing these provisions. Furthermore, the principles of direct applicability, direct effect and supremacy, combined with the preliminary reference procedure (Article 234) and the Commission's complaints procedure, creates a strong link between EU law and national law. Culturally, the SEM project has established a strong ideological commitment to guaranteeing the four freedoms. The extent to which the Single Market coalition is institutionally powerful equips them with the means through which they could undermine the deep and policy core belief system of the socio-cultural coalition. For example, the ruling in Bosman struck at the heart of the socio-cultural coalition's belief system.

The socio-cultural advocacy coalition is a coalition of convenience. This restricts their ability to act as a cohesive force but it does allow them to exploit a wider range of institutional venues. In particular, the coalition has exploited (1) the right of policy initiative within the Education and Culture Directorate; (2) the Parliament's legislative, scrutiny and budgetary powers; (3) the primary and secondary law-making functions of member states; (4) soft law including Treaty Declarations, Presidency Conclusions, political guidelines and Commission policy papers; (5) Council Presidency agenda setting; (6) the use of formal sports forums/sports conferences such as the European Sports Forum and the EU Conference on Sport; (7) the strength of positive (socio-cultural) integration post-Maastricht; and (8) related policy subsystems such as the health, audio-visual, education and youth. The involvement of the member states within the coalition has been significant. This has equipped the coalition with the power of political pressure and Treaty revision. Accordingly, the socio-cultural coalition also possesses the ability to adopt measures which could undermine the deep and policy core belief system of the Single Market regulators. A revision to the Treaty granting sport an exemption from EU law would undermine the uniform application of the four freedoms and create a precedent for further claims of special treatment by a range of commercial sectors. In circumstances where both coalitions possess the ability to undermine the belief system of their rival, coalition mediation is likely (see below). 


\section{Empirical contributions}

The tension between the EU's regulatory and political policy ambitions for sport has driven the development of today's EU sports policy. This policy is not however legally rooted in the Treaty. In other words, sport is not mentioned in the legally binding chapters of the Treaty. As such, EU sports policy lacks a legislative framework even though the development of one remains a possibility for the future (see below). The defining characteristic of modern EU sports policy is judicial not legislative. The construction of separate territories and hence EU sports law is at the heart of the EU's policy towards sport. This allows both the regulatory and political policy strands of EU sporting activity to co-exist. The above analysis, focusing on subsystem politics, actors and institutional resources allows us to piece together the relationship between these themes and establish a methodology for understanding how changes in EU sports law will affect the future direction of EU sports policy and vice versa.

\section{Sport and EU law: Single Market sports regulation}

Within national legal systems established general legal principles deriving from criminal law, contract law, the law of torts, public law, administrative law, property law, competition law, company law and fiscal law have gradually impinged upon the operation of sport. This process of juridification appears to be closely associated with the commercialisation of sport, although the relationship between sport and the law has a long history. Issues such as public order and sport, drugs and sport, safety in sport, disciplinary measures in sport, conduct in sport and wider issues relating to restraint of trade and anti-competitive behaviour in sport are today common features of the national legislative and judicial landscape. The internationalisation of sporting competition and finance combined with the development of the EU has internationalised juridification. Article 3 of the EU's founding Treaty specified that the activities of the Community shall include 'an internal market characterised by the abolition, as between member states, of the obstacles to the free movement of goods, persons, services and capital' and 'a system ensuring that competition in the internal market is not distorted'. Further Treaty Articles elaborated these goals, as did the passing of secondary legislation and the case law decision making of the ECJ. Although the Treaty did not refer to sport with the list of Community activities contained in Article 3 , the consequences of sports commercialisation became felt as EU provisions on the free movement of persons, services and competition law became applied to sport. The ECJ rulings in Walrave, Donà, Heylens and Bosman firmly established sports relationship to EU law whenever it was practised as an economic activity. The cases involved the application of established legal principles to sporting situations. As such, the rulings, based on a Single Market model of regulation, did not create a discrete area of sports law. 
The politics of sports regulation: re-asserting socio-cultural values

The relationship between sport and EU law has been forged through the strength of negative integration within the EU's constitutional structure. Observing the first decade of European integration, Pinder argued that the 'free trade ideology is firmly built into the system, but the planning ethic is no more than a possibility for the future' (Pinder 1968: 98). In other words, the socio-cultural dimension to European integration was considered a secondary goal to that of securing economic integration. As Featherstone observes, this economic path to integration has undermined popular support for the integration project (Featherstone 1994). The sheer existence of the Adonnino report was a formal acknowledgment by the EU that it had neglected the social and cultural dimensions of European integration. The growing legitimacy crisis within the EU would, unless addressed, fundamentally undermine the market-based achievements of integration. The people's Europe project was an attempt by the EU to address this issue by 'reconnecting' with its citizens.

The 1986 Single European Act and subsequent Single European Market project significantly advanced economic integration and laid the foundations for the birth of the single European currency. The 1992 Maastricht Treaty was a turning point for the EU. The completion of the SEM and the collapse of Communism offered the EU an opportunity to push for the launch of the single currency. However, the legitimacy question had not been tackled, potentially calling into question the viability of major EU projects such as the launching of a new currency. The Treaty adopted a series of measures designed to confront the legitimacy question. The Treaty expanded its range of social and cultural activities by granting a new legal base for culture, education, public health and consumer protection. Existing policies with a social expression such as environmental and cohesion policy were strengthened. The concept of European citizenship was created and the powers of the directly elected Parliament were increased. The name of the organisation also changed - from European Community to European Union. The name change reflected a shift in emphasis away from a Community established on economic foundations to a Union underpinned by social values. In short, Maastricht represented an attempt to change the cultural context of integration.

The Maastricht ratification crisis demonstrated the extent to which the EU's attempt to connect with its citizens had failed. The 1997 Amsterdam Treaty again re-visited the socio-cultural context of integration. However, wracked with division over the extent to which the EU needed reforming in preparation for enlargement, the EU adopted a cautious approach. Provisions on openness, employment, the image of EU, respect for human rights, the simplification of the Treaty, bringing the EU closer to the people, sex equality, environmental protection and anti-discrimination measures were agreed. The Declaration on Sport was also annexed to the Treaty. More 
concrete decisions on institutional reform were delayed until the 2000 Nice Treaty.

Treaty revisions have altered the cultural context of integration. The list of activities contained within Article 3 now extends beyond the scope of negative integration. The Treaty also contains a commitment to promote positive integration. In this connection, Article 3 includes activities of a more social and cultural nature, even though sport is not explicitly mentioned. The relationship between sport and the EU has been affected by the forces of negative and positive integration - the twin engines of European integration. The imbalance in favour of negative integration contributed to the emergence of a specific sports policy subsystem within the EU. In particular, the formation of the socio-cultural coalition with specific political sports policy objectives linked to the Adonnino agenda has greatly influenced the nature of EU involvement in sport. Since Bosman members of the socio-cultural advocacy coalition have used a variety of legal, semi-legal and non-legal measures to challenge the essentially economic and market-based definition of sport adopted by the Single Market coalition. By co-opting institutionally powerful members (such as the member states) into the socio-cultural coalition, it has been able to exploit a growing range of institutional venues in order to seek re-definition. In circumstances where two advocacy coalitions operating within the subsystem are both institutionally privileged, mediation is likely. The result of this mediation has seen the birth of a discrete area of sports law operating within the context of a more holistic EU sports policy.

\section{EU sports law and policy}

The Bosman ruling was a turning point for sport. It led to the creation of the sports policy subsystem. Actors unhappy at the economic Single Market approach the ECJ adopted in relation to sport, co-ordinated their activity to seek greater protection for sport from the application of EU law. As each coalition possessed the ability to undermine each other other's deep and policy core belief systems, coalition mediation took place. Past experience, perceptions of future losses and the cultural norm within the EU of mutual adjustment facilitated mediation. In other words, the unsatisfactory prospect of potential coalition confrontation led to a learning process taking place within the subsystem. The Education and Culture Directorate emerged as a key venue through which mediation between the two advocacy coalitions has occurred. In 1999, the Commission organised the first EU Conference on Sport to complement the annual European Sports Forum. The Directorate has also been active in elaborating the general policy of the member states in the form of policy papers. The Helsinki report on Sport represents the Commission's current position and the birth of a de facto if not de jure EU sports policy. From within the mediation and learning process has emerged compromise between the coalitions. The goal of mediation was to find grounds for compromise without undermining the deep and policy 
core beliefs of both coalitions. As such, compromise has taken place within the secondary aspects of the coalitions belief systems. Coalition compromise has resulted in the following developments.

First, coalition compromise has resulted in the birth of a more coordinated EU sports policy located within secondary aspects of both coalitions belief systems. It is not a policy which is legislatively rooted. In other words there is no Article or protocol on sport within the Treaty. This move is resisted by the Single Market coalition as it would undermine their deep and policy core beliefs. Therefore sports policy is still essentially regulatory in nature. Although the socio-cultural aspects of sport can be harnessed to implement other policy goals in the EU, the lack of a Treaty base for sport inhibits the development of a redistributive strand in sports policy. Disagreement over the merits of this development exist within the sociocultural coalition.

Second, the cornerstone of EU sports policy is the separate territories concept. Separate territories refers to the creation of spheres of jurisdiction for sports bodies and the law. One territory is sporting autonomy. Within this territory the EU will either not intervene judicially or accept justifications for exemptions from the application of law. The other territory is judicial intervention. Within this territory, EU law will continue to be applied.

Third, the development of the separate territories approach marks the birth of EU sports law. As Beloff et al. argue, 'the cornerstone of what could be called the founding principles of sports law is the definition of respective territories of the courts and the bodies which govern sport' (Beloff $e t$ al. 1999: 4). The construction of separate territories necessitates sport being treated differently to other sectors, another defining characteristic of sports law. Even though historically both the ECJ and the Commission have acknowledged the special characteristics of sport in their case law, EU sports law is a very recent phenomenon.

Finally, the above developments have had practical effects on the nature of EU sports regulation. Previously based on the Single Market model, the separate territories approach has introduced greater socio-cultural values into the approach. Again, this new approach to sports regulation is confined to the secondary aspects of the coalitions belief systems. Nevertheless, by compromising in this area both coalitions are protecting the fundamentals of their deep and policy core beliefs.

The above developments are the product of activity within the sports policy subsystem - hence the need for subsystem analysis. Four strands of EU activity illustrate how the construction of this approach has occurred.

Bureaucratic measures The activities of the Education and Culture Directorate have been instrumental in elaborating the policy objectives of the member states and establishing an embryonic separate territories framework. By establishing dialogue with the sports world through the organising 
of the first EU Conference on Sport in 1999 and managing the annual meeting of the European Sports Forum, the Commission has been able to prepare the Helsinki report on Sport for the member states. The paper argued that 'sport must be able to assimilate the new commercial framework in which it must develop, without at the same time losing its identity and autonomy, which underpin the functions it performs in the social, cultural, health and educational areas'. ${ }^{2}$ The concept of separate territories has therefore received Commission approval.

Legislative measures Separate territories has also received legislative and quasi-legislative attention. The Parliament's revision of the Television Without Frontiers Directive represents the most formal attempt to have sport treated differently to other sectors. By permitting the establishment of protected national lists, the Directive has granted sport an exception from the general principle of free movement of services in trans-frontier broadcasting. ${ }^{3}$ Member state activity in the legislative field has been confined to soft law. The Declaration on Sport annexed to the Amsterdam Treaty and subsequent soft law measures culminating in the Nice Declaration on Sport demonstrate the member state's desire to see the separate territories concept more widely employed. The Nice Declaration argued that 'even though not having any direct powers in this area, the Community must, in its action under the various Treaty provisions, take account of the social, educational and cultural functions inherent in sport and making it special, in order that the code of ethics and the solidarity essential to the preservation of its social role may be respected and nurtured'. The Declaration represents the clearest indication yet from the member states that the rules of sport bodies which are designed to maintain a competitive balance between participants should be treated differently by EU law to similar restrictions in other sectors. Until the member states have had time to observe the impact of the separate territories approach, they have shied away from adopting harder measures.

ECJ jurisprudence The ECJ's involvement in the construction of the separate territories concept is potentially most significant. The ECJ has in previous sports related case law acknowledged the social significance of sport. For instance in Bosman the ECJ argued that 'in view of the considerable social importance of sporting activities and in particular football in the Community, the aims of maintaining a balance between clubs by preserving a certain degree of equality and uncertainty as to results and of encouraging the recruitment and training of young players must be accepted as legitimate'. ${ }^{4}$ Nevertheless, the rulings in Deliege and Lehtonen mark a more substantial application of the view expressed in Bosman. In Bosman, the ECJ defined the operation of the international transfer system for football and the use of nationality quotas in sport as falling within the EU judicial territory. In Deliège and Lehtonen the ECJ has identified selection criteria and 
transfer windows as falling within the territory of sporting autonomy. In essence Deliège and Lehtonen establish that the rules which sports bodies retain competence over concern those which are inherent in the conduct and/or organisation of sporting events. Despite the limitations to the rulings examined in Chapter 4, they do open up the possibility for sports bodies to connect sporting interest arguments with public interest justifications. This was the conclusion of the Advocate General in Lehtonen. If sports bodies can be successful in this connection, this could act as a vehicle for the expansion of the sporting autonomy territory and the contraction of the judicial intervention territory.

Commission quasi-jurisprudence The concept of separate territories is also beginning to establish itself in the field of competition law. The February 1999 paper on the application of competition rules to sport was the Commission's first significant exploration of the separate territories approach. ${ }^{5}$ The paper has informed subsequent Commission analyses of alleged restrictive practices in sport. A review of the case law within sports exploitation, contest and supply markets illustrates the development of the separate territories approach within competition law. The exploitation market concerns the collective sale of sports rights, exclusive contracts, the purchase of sports rights, the transmission of the rights, ticketing practices and merchandising arrangements. The Commission's general approach to the exploitation market has been two-fold. First, it has generally held that sports rules are covered by the scope of Article 81 and 82. Second, it has however been willing to recognise the specificity of sport by informally clearing or formally exempting such rules. The contest market refers to the organisation of the sporting contest. The Commission has been sympathetic to rules which seek to maintain the single structure model of sport and rules restricting multiple club ownership and club relocation. In the Formula One case the Commission separated the FIA's regulatory and commercial functions. Commission investigations into sport's supply market have essentially concentrated on the operation of the international transfer system for football. The Commission initially made it clear that it was not prepared to accept alternatives to the transfer system that compromised EU law. However, the March 2001 settlement on transfers reflects a more sympathetic approach to sport. The Commission has accepted the argument that restrictions on player mobility and restrictions on the ability of clubs to employ players without obstruction can be justified in terms of maintaining a competitive balance between participants. The Commission has therefore acknowledged the specificity of sport within the context of EU competition law and further defined the separate territories concept.

Taken as a whole, the body of 'hard' sports law reviewed above does not amount to a great deal - hence the need to refer to the 'birth' of EU sports 
law and policy. Nevertheless, a system of law governing the practice of sport is emerging in the EU of which the use of soft law is a particular feature. Within the context of mediation between coalitions, the use of soft law allows both coalitions to protect their deep and policy core belief systems. For the Single Market coalition, soft law does not legally challenge entrenched Treaty principles. Harder measures such as the use of Treaty exemptions for sport runs the risk of undermining the fundamentals of their belief system. For the socio-cultural coalition, soft law, although less satisfactory, allows for the construction of the separate territories approach which, if defined favourably, can safeguard sports autonomy. Of course, the use of soft law by the EU is not without its critics (Kinsella and Daly 2001).

\section{The future of EU sports law and policy}

Current EU sports policy based on the separate territories concept is therefore located within the secondary aspects of the coalitions belief systems. Is this reconciliation between coalitions and hence current EU sports policy sustainable? Might EU sports policy break out of the confines of the mediated approach? The answer lies not only in the extent to which the separate territories approach has satisfied and will continue to satisfy the objectives of both coalitions but also the feasibility of the coalitions exploiting further institutional venues in order to affect further policy change. The separate territories approach allows the socio-cultural coalition to claim some special status for sport within the Treaty framework without compromising the line of reasoning developed by the Single Market coalition in relation to the economic status of the sector. As such, the separate territories approach has the potential to satisfy the objectives of both coalitions. However, whilst the current approach offers a degree of short-term stability, is more strategic thinking required?

First, due to the predominance of soft law, the separate territories approach is not fully enshrined in law. As such, the definition of the separate territories is fluid. This leaves the regulatory environment within which the socio-cultural coalition operates confusing and prone to legal challenge. Even if the Commission employs the exemption criteria more widely to the sports sector, the ECJ still remains a venue for litigation. Competition law exemptions will still need to satisfy the requirements of Article 39. The separate territories approach is therefore legally fragile and susceptible to being undermined. This may encourage members of the socio-cultural coalition to venue shop for a hardening of the separate territories approach. In this connection tactical differences within their secondary aspects of their belief system may yet hamper them (see below).

Second, does the case-by-case approach satisfy the Single Market coalition's (in particular the Commission's) desire to reduce the number of sportsrelated cases coming before them? Only by providing clear guidelines on 
exemptions can the Commission hope to avoid the resource sapping caseload that has burdened it throughout the late 1990s.

The future of sports law and policy is likely to be influenced by developments external and internal to the EU. Externally, a change in the economic status of sport will affect the policy debate. Just as Bosman was influenced by (and indeed promoted) the commercialisation of sport, a downturn in the economic wealth of sport could strengthen public interest and solidarity arguments for the expansion of the sports autonomy territory. However, the post-ITV Digital financial crisis within the English Football League does not seem to have advanced these arguments. The case for a Division One breakaway is increasingly being made which, if successful, would undermine the concept of solidarity between all members of the Football League.

Within the context of the EU, the forthcoming 2004 intergovernmental conference offers the socio-cultural coalition a possible venue for harder measures to be entrenched within a new Treaty. The year 2004 is likely to be influenced by the staging of major sporting events in Europe. The Olympic Games are to be held in Greece and the football European Championships will also be staged. Furthermore, 2004 is due to be declared European Year of Education Through Sport, thus giving sport a high profile during the IGC discussions. ${ }^{6}$ Following the Year of Education through Sport initiative, the Commission intends to prepare a proposal implementing a December 1999 Council resolution on education and sport. ${ }^{7}$ In previous reports, the EU has identified the excessive commercialisation of sport as an actual and potential threat to sports social, cultural and educational values. ${ }^{8}$ The sociocultural coalition therefore has a strong case in arguing that current sporting rules which are designed to maintain a competitive balance within the sector but which prima facie contravene EU law require a greater level of protection than that offered by the current approach. In this connection, the separate territories approach could develop in a number of directions.

The option closely related to the status quo is for the Commission to make greater use of the individual exemption procedure outlined in Article 81(3). The current soft law approach could harden with the adoption of formal decisions to close cases. Failing that, guidance in the form of notices could provide further guidelines to sport. For the Commission, this approach would help reduce its sports-related caseload whilst also lessening the threat of the member states adopting harder Treaty measures - an option traditionally resisted by the Commission. For the socio-cultural coalition, the use of individual exemptions offers the potential for sport to incrementally gain a partial exemption from EU law through the expansion of the sporting autonomy territory.

The second option would be for the member states to use soft law to place added pressure on the ECJ and the Commission to extend the sporting autonomy territory within the separate territories approach. In particular, the member states could strengthen the Amsterdam Declaration through the 
use of Presidency Conclusions at the end of European Council summits or through a new Declaration annexed to a revised Treaty. As with the first option, this relatively uncontroversial move is likely to be favoured as it not only offers the socio-cultural coalition the most realistic prospect of progress but it also allows the Single Market coalition scope to compromise with socio-cultural actors without undermining the fundamental principles on which the Single European Market is based.

A third option would be for the Commission to issue a block exemption Regulation for sport which would exempt particular sporting practices from the application of Article 81. For such a move to be effective sufficient case law experience must first be gained and a wide consultation process established. As this is a very lengthy process, the establishment of such a Regulation is therefore a longer-term possibility. For some 'moderate' sociocultural actors (particularly the sports governing bodies) this option is favoured as it offers sport's specific characteristics legal protection from the application of competition law. It is however an option unlikely to be sanctioned by the Competition Policy Directorate. Previously the Commission has argued that such an exemption is 'unnecessary, undesirable and unjustified' (Schaub 1998). Furthermore, wide consensus on the need for block exemptions is preferred by the Commission. Such consensus is absent. However, precedents for block exemptions do exist and potentially such exemptions, if carefully conceived, can reduce the number of individual exemption requests. The under-resourced Commission would welcome any significant reduction. The longer-term prospect of a block exemption for sport should therefore not be discounted. As EU sports law develops, so a line of reasoning on sport will emerge which could potentially persuade the Commission to explore the feasibility of an exemption.

Fourth, the member states could attach a protocol on sport to the Treaty. The EU has adopted such protocols to: (1) address specific member state concerns (as with the social protocol); (2) to provide exemptions to Treaty principles (as with the Danish Second Homes protocol); or (3) to limit the effects of a Court ruling (as with the Barber protocol). Clearly, all three instances pose problems. In the first instance a precedent for a more flexible a la carte Europe is set. In the second instance, a precedent is set for allowing a range of industries to claim 'special status'. In the third, a potentially undemocratic precedent is established whereby member states interfere in Court rulings. The protocol approach is supported by the moderates within the sociocultural advocacy coalition and has gathered some support within member state capitals. A joint FIFA/UEFA task force examined the protocol proposal. UEFA Chief Executive, Gerhard Aigner explained, 'we are not seeking to change EU law by having the Bosman ruling repealed but what we do want is a sporting protocol to the European Treaty which would allow the EU to apply certain exemptions in sport'. ${ }^{9}$ UEFA's support for a sports protocol was further elaborated in their brochure, 'A Vision for European Sport: 
The Case for a Sports Protocol' (Blackshaw 2002). UEFA sees a protocol as a method of legally rooting the expansion of the sporting autonomy territory whilst maintaining distance from the Treaty. An Article for Sport would entail much greater supranational involvement in sport. However, the protocol option is not favoured by the Single Market coalition. The Commission is concerned that such a move would undermine the legal foundations of the Single Market. It is uncertain whether the member states could muster the required unanimous support for such a move.

Fifth, sport could be added to the list of EU activities outlined in Article 3 of the Treaty. Article 308 of the Treaty states that, 'if action by the Community should prove necessary to attain, in the course of the operation of the market, one of the objectives of the Community and this Treaty has not provided the necessary powers, the Council shall, acting unanimously on a proposal from the Commission and after consulting the European Parliament, take the appropriate measures'. Combining Article 3 with this 'catch-all' Article would permit action by the EU in sports matters if it was felt appropriate for the attainment of one of the objectives of the Treaty.

The sixth option involves the member states placing limits on the freedom of movement for workers (sportsmen and women) by amending Articles 39, 43 and 49. In addition, partial or full exemptions from the Treaty's Competition Policy provisions could be established by amending Articles 81 and 82. Both options are resisted by the Single Market coalition as they would undermine their deep and policy core beliefs. Furthermore, the many socio-cultural actors, including the Parliament, are reluctant to restrict the free movement of sports men and women. The rights afforded to EU citizens are seen as universal rights. The chances of success are therefore limited.

The seventh option involves including sport within the remit of Cultural policy (Article 151). The assumption underlying this approach is that sport can be equated with culture, even though this analogy was rejected by the ECJ in Bosman. ${ }^{10}$ Furthermore, sport could be incorporated within Article 149 on Education, Vocational Training and Youth. Whilst this option has some maximalist support, it fails to address the sports specific concerns of the socio-cultural coalition. The cultural option is traditionally supported by the Parliament.

A related eighth option would be for the member states to create a new protective Article for Sport in a revised Treaty. Not all members of the sociocultural coalition agree on this option. The maximalists favour the development of a common sports policy through the establishment of a legal base for sport (although see option seven). An Article for sport would not only shape and stabilise the legal environment in which sport operates, it would also provide a legal base for the development of sports funding programmes. These programmes could assist in the implementation of maximalist policy goals whilst providing sports bodies with an alternative source of income. The moderates do not support the development of a common sports policy 
but do wish to see the legal environment clarified through the adoption of a Treaty protocol on sport which would place a legal obligation on the EU to recognise the specificity of sport within its legal framework. Finally, the minimalists (particularly the Governments of Britain, Sweden and Denmark) do not see a greater role for the EU in sport as Treaty incorporation for sport would contradict the EU's claims of subsidiarity. Sufficient flexibility exists within the EU's legal framework for the EU to recognise the specificity of sport. As options seven and eight require Treaty revision, they require the unanimous support of the member states. This is a significant hurdle.

A ninth option lies within the wording of Article 86(2) of the Treaty. Article 86(2) potentially allows for an exemption from Treaty principles if undertakings entrusted with the operation of services of general economic interest or having the character of a revenue-producing monopoly can demonstrate that the application of the competition rules would obstruct the performance of tasks assigned to it. The prospects of such a move are however remote. Member states would have to take legal steps to create these entrusted sporting undertakings, as undertakings created by private initiative would be excluded. It is not only unlikely that member states would be willing to take such a step, it is also unlikely that sports organisations would see this move as desirable.

Finally, parallels can be drawn with the experience of sports treatment under US law. The debate concerning the application of competition rules to sport has also taken place in the USA. In the USA, two arguments have been advanced to support sports claim for an exemption from competition law. The rule of reason approach 'is based on the assumption that the efficiency promoting effects of certain agreements (amateur, junior sport, solidarity, competitive balance) are more important than the possible competitive distorting effects of the restrictions that arise from the agreement or behaviour'. ${ }^{11}$ The rule of reason approach does not sit comfortably with EU competition law as the Commission can achieve the balance between proand anti-competitive rules through the exemption criteria. The second argument concerns the so-called single entity theory. This theory rests on the assumption that sport is a single economic entity. This means that anticompetitive measures may be tolerated within the sector. In the USA the US soccer federation has succeeded with this classification (Gray 2000: 281, Cairns 2002: 74). The Danish Co-operatives case provides a European parallel of sorts. Here an agricultural co-operative was permitted to prohibit their members from participating in alternative agricultural co-operatives as the restriction benefited competition. The logic of the single entity has not, as yet, been transferred to sport. In the view of Egger and Stix-Hackl, 'although sporting contests cannot be carried out by one club alone, but only by several clubs, nevertheless there is no 'single entity'. This particularity of football sport does not change the fact the individual clubs are undertakings. That the clubs are not to be regarded as a unit is shown precisely by their 
behaviour in connection with transfers of players, where the different interests of the individual clubs are especially clearly visible. It follows from the independence of the clubs that there is thus no question of 'internal' competition within a group of undertakings' (Egger and Stix-Hackl 2002: 86).

\section{Conclusions}

The application of the actor-centred institutional methodology employed throughout this text allows the researcher to judge with greater, although not total, certainty the future direction in which EU sports law and policy will develop. The methodology has asserted the need for subsystem analysis. By identifying actors and their belief systems and the institutional resources available to them, the researcher can better understand coalition strategy and the chances of strategic success. The Single Market coalition and the socio-cultural coalition are relatively evenly matched in terms of institutional resources. The socio-cultural coalition is however hampered by the diversity of opinion within the coalition. Nevertheless, both coalitions possess the institutional resources to undermine each other's deep and policy core belief systems.

Deeply embedded within the EU is the institutional norm of mediation. As a diverse multi-competence, multi-national and multi-level organisation, the EU has developed channels for mediation. However, unlike as is commonly portrayed in the media, the EU is not simply a venue in which all beliefs are sacrificed. The methodology employed in this text indicates the extent to which the coalitions will compromise. It has been claimed that the coalitions will seek to protect their deep and policy core beliefs above anything else. To fundamentally compromise these beliefs would be to call in question their reason for existing. Nevertheless, some under-resourced coalitions may be faced with having to accept compromise in their deep and policy core belief system. In the case of the sports policy subsystem, both coalitions are well resourced. As such, it is to the secondary aspects of their belief systems that the analysis must turn. The future direction of policy is likely to be confined to this field.

In the case of sport, the mediation resulted in the construction of the separate territories approach, an essential characteristic of EU sports policy. In order to protect their deep and policy core beliefs, both coalitions accepted the tactic of defining a territory of sporting autonomy and a territory of legal intervention. This distinct legal approach to sport marks the birth of EU sports law. The separate territories approach is quite a simple concept. The rules of sport are either sporting in nature and as such are not in breach of EU law (either falling outside the scope of EU law or are able to be justified and as such exempted from it) or they are commercial in nature and could potentially fall foul of EU law. However, as the book has already discussed, the precise definition of what constitutes sporting rules and commercial rules 
is problematic. Nevertheless, the future of EU sports law will be concerned with exactly this definitional issue. Where will the boundaries of the separate territories lie?

The ten policy options outlined above tend to stress strategies to expand the sporting autonomy territory. However, as has been demonstrated above, the socio-cultural coalition is a coalition of convenience. It lacks a cohesive approach to sport. Whilst the diversity of the coalition allows for the greater potential for venue exploitation, it also poses practical problems of coordinated action. The lack of consensus over Treaty incorporation for sport illustrates such divisions. It is therefore possible that the separate territories approach can be undermined through the contraction of the sporting autonomy territory and the expansion of the territory for judicial intervention. However, in the short to medium term, the sporting autonomy territory is unlikely to contract. By accepting the principle of separate territories, the Single Market coalition has in effect sanctioned the modest expansion of the sporting autonomy territory.

As changes in EU sports law are likely to be confined to the secondary aspects of the coalitions belief systems, only options one and two are likely to be pursued in the short to medium term. The Commission is therefore likely to continue to make use of the negative clearance and individual exemption criteria outlined in Articles 81 and 82. This allows the Commission to respond to socio-cultural pressure for an acknowledgement of sports special characteristics whilst not undermining the concept of free competition in the Single Market. Such case law will allow for greater clarity over the definition of the separate territories, although the likely continued use of soft law may undermine this. The member states are also likely to confirm their desire to see the sporting autonomy territory expanded. Again, soft law in the form of Presidency Conclusions or Treaty Declarations is likely to be the preferred option. Such an approach does not fundamentally challenge the deep and policy core beliefs of the Single Market coalition and it avoids the problematic question of how to secure consensus within the socio-cultural coalition over the relationship between sport and the Treaty. Member state soft law is also likely to guide the jurisprudence of the ECJ without the need to take Treaty bound measures. The ECJ's role is crucial to the development of EU sports law. Recent ECJ case law has contributed to the separate territories approach by making a distinction between sports rules which are inherent to the game and rules which are of a commercial nature. With further political pressure, the 'sporting' justification argument may develop into a 'public interest' justification. Finally, soft law could be used as justification for sport to be integrated into a range of other EU activities as a way of safeguarding the special characteristics of sport and promoting wider socio-cultural policy goals. The Commission has identified doping and youth activities as two such areas in which sport plays a significant role (see below). ${ }^{12}$ By recognising the social, cultural, educational and health 
qualities of sport, the EU can implement sports policy goals in these neighbouring subsystems. This can be achieved without the problematic option of developing a fully fledged common sports policy.

The tactic of dispersing sports policy within neighbouring subsystems is however problematic. As illustrated above (and below), maximalist members of the socio-cultural coalition argue that a sports policy unattached to the Treaty leaves the legal environment uncertain. In addition, it does not grant sport a specific budgetary line. Any extension of the EU's involvement in sports policy must therefore be carefully conceived. In UK v. Commission, the ECJ held that each budget item must have a legal base. ${ }^{13}$ This ruling resulted in the Commission abandoning its sports-related Eurathlon programme. Subsequent developments in sports policy requiring a budgetary line have had to navigate within the EU's rigorous budgetary rules. On these grounds, the Commission's 2002 call for proposals concerning the development of a Community policy in the field of sport appears legally fragile. ${ }^{14}$ However, it relates to preparatory measures falling within the meaning of the Interinstitutional Agreement on legal bases and the implementation of the budget. ${ }^{15}$ This agreement stipulates that any budgetary initiative must be supported by a 'basic act' of secondary legislation. As sport is not legally rooted in the Treaty, the EU has not passed sports specific legislation and as such the basic act requirement has not been fulfilled. The soft law initiatives which have characterised much of the development of EU sports policy are not considered 'basic acts'. However, appropriations relating to preparatory measures intended to prepare proposals with a view to the adoption of future Community actions are permitted subject to certain limitations. These preparatory measures must still however fall within the competence of the EU. ${ }^{16}$ The Commission has interpreted this as justification for their call for preparatory measures concerning how sport relates to doping and youth activities. Should this activity fail to gain a legal base within three years, the funding would however have to cease. The budgetary 'rules of the game' therefore place further limits on the future scope of EU sports policy. Nevertheless, the extent to which the EU has acquired a greater socio-cultural expression in its policy remit since Maastricht means that sport now sits more comfortably within the EU's policy architecture.

Effectively, an expanded separate territories approach affords sports organising bodies considerable influence over the sport which they organise. Previously this power has not been exercised wisely - hence the juridification of sport. As Weatherill observes, it has been the choices made by sport that has driven juridification, not the EU (Weatherill 2000b). The Helsinki report on sport has already made a plea for reform at the level of the sports organisations. In particular, the report suggested that sporting federations should more clearly define their 'missions and statutes' in order to demonstrate that they themselves have taken measures to protect and nurture those special characteristics of sport that they are asking the EU to protect. Sports 
bodies need to address a number of issues. First, the rights of players need greater protection within the constitutions of sports bodies. This also refers to their ability to appeal the decisions of sports bodies. Not all sportsmen and women conform to the multi-millionaire stereotype. Without such protection, the EU will continue to be regarded as a venue for legal redress. Second, sports bodies need to demonstrate a greater commitment to solidarity in sport. By doing so, sport can rely more satisfactorily on the sporting justifications argument when issues of a commercial nature are being examined. Finally, the interests of fans should be safeguarded. Although sports bodies have an obligation to maximise the commercial potential of sport, the extent of permitted commercialisation should be proportionate to the requirements of the solidarity function of the sports bodies. As Foster argues, 'without these minimum conditions for limited autonomy, sports federations should expect further legal regulation to ensure that sport as a business is still run partly for the love of the game and not just for the love of money' (Foster 2000a: 64). Above all, sport should finally recognise that the EU is remarkably receptive to claims of special treatment. Working within the sports policy subsystem has allowed sports governing bodies to make these claims more coherently. It has also alerted sport to what is and what is not possible. Subsystem analysis demonstrates that currently the mediated approach taking place within the secondary aspects of both coalition's belief systems offers sport the best venue for protecting sports rules. This acceptance requires sport to abandon the rather feeble 'we know best' claim. It requires a psychological jump on the part of both sport and the EU institutions to acknowledge that increasingly the ECJ and the Commission are emerging as a supranational sports regulator - not in the sense of establishing a legislative framework for sport but as a clearing-house for sports rules. It is arguable that the EU's role as a sports regulator extends beyond even that of a clearing-house for sports rules. Although the Helsinki report's 'model of sport' cannot be imposed on sport, measures adopted by sport which undermine its principles are unlikely to be cleared by the EU. Although all parties reject the desirability of a supranational sports regulator, it is surely difficult to argue that current EU sports policy is not based on this reality.

The trend towards supranational sports regulation may in future be complicated by the Commission's proposal to amend the procedures for applying competition law. ${ }^{17}$ This will undoubtedly affect the future definition of the separate territories. The proposal to devolve the exemption system outlined in Article 81(3) to national courts and national competition authorities will draw into the sports policy subsystem many more actors. Although the current separate territories landscape will inform their judgements, the lack of hard law within the subsystem and the lingering shadow of Bosman casts doubt on the longer-term viability of separate territories in its current form. Although private enforcement of competition law is not new, the wider 
involvement of national authorities could result in increased venue shopping from litigants. Any contraction in the territory of sports autonomy as a result of the involvement of national regulatory authorities is likely to lead to further venue shopping by the socio-cultural coalition as well. As further subsystem activity remains a possibility for the future, the construction of the separate territories approach may not therefore establish a settled legal environment for sport. Law will undoubtedly play a prominent feature within the sports policy subsystem in the future. However, as Weatherill concludes these issues should not mask the central question which involves 'the short sightedness of (some) clubs in pursuing commercialisation without adequate respect for the nature and purpose of sport in society' (Weatherill $2000 \mathrm{~b}$ ). Although sport has so often been portrayed as a victim of European integration, it has been sports own actions (or lack of them) which has driven the internationalisation of sports law.

\section{Notes}

1 The Convention is currently gathering opinion on possible Treaty change. The Nice Treaty committed the EU to a further intergovernmental conference in 2004.

2 Para. 4. Com (1999) 644, 'Report from the Commission to the European Council with a View to Safeguarding Sports Structures and Maintaining the Social Significance of Sport within the Community Framework: The Helsinki Report on Sport', 1/12/99.

3 Although other events of major importance to society can also be listed and protected.

4 Para. 106. Case C-415/93, Union Royale Belge Sociétés de Football Association and others v. Bosman [1995] ECR I-4291.

5 DN: IP/99/133, 'Commission Debates Application of Its Competition Rules to Sport', 24/02/99.

6 COM (2001) 584 Final, 'Proposal for a Decision of the European Parliament and of the Council Establishing the European Year of Education Through Sport', $16 / 10 / 01$.

7 OJ C 8 12/01/00.

8 'Development and Prospects for Community Activity in the Field of Sport', Commission Staff Working Paper, Directorate General X, 29/09/98. 'The European Model of Sport'. Consultation Document of DG X. 1998. COM (2001) 584 Final, 'Proposal for a Decision of the European Parliament and of the Council establishing the European Year of Education through Sport', $16 / 10 / 01$.

9 UEFA News Release 13/4/00.

10 Para. 78. Case C-415/93, Union Royale Belge Sociétés de Football Association and others v. Bosman [1995] ECR I-4291.

11 'The balance between the game and the money', Final Report. Study commissioned by the Netherlands' Ministry of Health, Welfare and Sports Directorate. Re-produced in Caiger and Gardiner (2000). 
12 See 'Preparatory Measures for a Community Policy in the Field of Sport', Call for proposals. DG EAC No. 33/02. See also COM (2001) 584 Final, 'Proposal for a Decision of the European Parliament and of the Council Establishing the European Year of Education through Sport, 16/10/01.

13 Case C-106/96, UK v. Commission ECR I-02729.

14 See note 12.

15 OJ C 344, 12/11/98. Subsequently replaced by OJ C 172/1, 18/06/99 (Interinstitutional Agreement of 06/05/99).

16 For a full review of the potential legal bases relating to sporting actions see Commission document 'Community Aid Programmes'. Available online at: http://europa.eu.int/comm/sport/doc/ecom/actions_comm_en.pdf

17 See COM (2000) 582 Final, 'Proposal for a Council Regulation on the Implementation of the Rules on Competition Laid Down in Articles 81 and 82 of the Treaty and amending Regulations (EEC) No. 1017/68, (EEC) No. 2988/74, (EEC) No. 4056/86 and (EEC) No. 3975/87. ('Regulation Implementing Articles 81 and 82 of the Treaty'), 27/09/00. 